\title{
POTENSI PENGEMBANGAN STANDAR NASIONAL INDONESIA (SNI) PRODUK FURNITUR DARI KAYU
}

\author{
Potential Development of Indonesian National Standard (SNI) \\ Wooden Furniture Products
}

\author{
Ari Wibowo dan Putty Anggraeni \\ Pusat Penelitian dan Pengembangan Standardisasi, Badan Standardisasi Nasional \\ Gedung 1 BPPT Lantai 12, Jalan MH. Thamrin No.8 Jakarta Pusat, Indonesia \\ Email : ari@bsn.go.id
}

Diterima: 26 Februari 2018, Direvisi: 19 April 2018, Disetujui: 23 April 2018

\begin{abstract}
Abstrak
Pasar domestik furnitur tumbuh pesat seiring pertumbuhan di sektor properti perumahan, kondominium, hal tersebut membuka celah impor di pasar lokal setidaknya dalam 5 tahun terakhir. Dalam rangka melindungi pasar domestik, meningkatkan daya saing industri furnitur dan mendorong peningkatan ekspor, Pemerintah memiliki peran penting untuk mewujudkan hal tersebut. Penerapan Standar Nasional Indonesia (SNI) merupakan salah satu kebijakan dan strategi penting Pemerintah untuk meningkatkan daya saing industri. Tujuan penelitian ini adalah untuk mengidentifikasi pengembangan SNI produk furnitur dari kayu sehingga diharapkan dapat memperkuat daya saing produk furnitur. Data sekunder diperoleh melalui desk study Sistem Informasi SNI, ISO, IEC, sedangkan data primer diperoleh melalui kuesioner, wawancara dan Forum Grup Discussion dengan peneliti di bidang Standardisasi dan Serangga. Hasil penelitian menunjukan bahwa national differences perlu menjadi unsur yang ada dalam persyaratan SNI produk furnitur. Iklim Indonesia memiliki suhu udara yang hangat namun memiliki kelembaban udara yang tinggi menjadikan surga bagi rayap, faktor iklim Indonesia (negara tropis) dapat menjadi faktor national differences bagi pengembangan SNI. Rayap, jamur dan bubuk kayu di Indonesia memiliki variasi dibanding negara subtropis, sehingga Uji ketahanan rayap, Uji hama bubuk kayu, Uji ketahanan jamur, Uji kestabilan dimensi, Uji kadar air perlu dikembangkan dalam SNI produk furnitur dari kayu. Saat ini terdapat 84 SNI produk furnitur yang terdiri SNI produk (33\%), metode uji (64\%) dan Standar Dasar (1,5\%), Lain-lain (1,5\%).

Kata Kunci: Standar Nasional Indonesia, national differences, furnitur, kayu.
\end{abstract}

\section{Abstract}

Domestic furniture market grew rapidly as growth in residential property sector, condominiums, it has opened an import gap in local market at least last 5 years. In order to protect domestic market, enhance competitiveness of furniture industry and encourage increased exports, Government has an important role to make it happen. SNI is one of Government's important policies and strategies to improve competitiveness. Research purpose is to identify SNI development of wooden furniture product so that it can strengthen competitiveness. Secondary data was obtained through desk study of SISNI, ISO, while primary data was obtained through questionnaires, interviews and FGD with researchers in field of Standardization and Insects. Result shows that national differences need to be an element in SNI requirements of furniture products. Climate Indonesia has a warm air temperature but has a high humidity of air makes a paradise for termites. Climatic factors (tropical country) can be a factor of national differences for development of SNI, Termap, mushroom and wood powder in Indonesia has variation compared to subtropical countries, so termite endurance test, pest test pests, fungus endurance test, dimensional stability test, water needs to be developed in SNI. Currently there are 84 SNIs of furniture products consisting of product SNI (33\%), test method (64\%) and Basic Standard (1.5\%), Others (1.5\%).

Keywords: Indonesian National Standard, national differences, furniture, wood.

\section{PENDAHULUAN}

Indonesia merupakan negara penting sebagai penghasil hasil hutan khususnya kayu, kayu tropis merupakan salah satu komoditi hasil hutan yang strategis sebagai bahan baku industri di dalam negeri dan penghasil devisa dari sektor non migas. Luas hutan di Indonesia mencapai 133.300.543,98 ha, mencakup kawasan suaka alam, hutan lindung, dan hutan produksi (Kementerian Kehutanan, 2010).

Kayu merupakan bahan organik yang bersifat keras dan secara alamiah terbentuk dari serat selulosa di dalam pohon. Kayu dapat 
digunakan untuk produk teknis, mulai dari tiang kayu olahan sampai produk jadi. Dalam pengertian yang lebih luas, kayu berupa potongan kayu atau serat, seperti papan serat kayu Oriented Strand Boards (OSB), kayu lapis (plywood), papan serat (fibreboards), papan yang direkatkan dengan semen (cement bonded particleboards), papan yang direkatkan dengan getah pohon (resin bonded particleboards atau chipboards), kayu komposit (SCL), flax boards, dII (Kementerian Perdagangan, 2013).

Kayu memiliki beberapa sifat sekaligus karakter yang tidak dapat ditiru oleh material atau bahan-bahan lainnya, dan suatu bahan yang diperoleh dari hasil pemungutan pohon-pohon yang ada di hutan, merupakan bagian dari pohon tersebut. Baik berupa berbentuk kayu pertukangan maupun kayu bakar (Rizki dkk, 2016). Furnitur sebagai produk artistik biasanya terbuat dari kayu pilihan dengan warna dan tekstur indah yang dikerjakan dengan penyelesaian akhir yang halus. Kayu yang di anggap bagus biasanya memiliki karakter yang kuat, keras, dan berwarna gelap. Sedangkan kayu yang tidak bagus memiliki karakter yang lunak, mudah dimakan rayap, dan warnanya terang (Samantha \& Sena, 2017). Salah satu indikator baik atau tidaknya suatu produk furnitur adalah kualitas permukaan kayu. Kualitas permukaan dari produk yang terbuat dari kayu adalah salah satu sifat yang paling penting dalam industri furnitur yang nantinya akan sangat berpengaruh pada proses manufaktur selanjutnya seperti proses finishing dan kekuatan sambungan adhesif kayu.

Sejak dibukanya ASEAN Free Trade Agreement (AFTA) sebagai kawasan perdagangan bebas negara-negara, ASEAN menjadi basis produksi pasar dunia (Kementerian Perdagangan, 2013). Dengan kondisi yang ada untuk meningkatkan daya saing ekonomi produk Indonesia harus dapat mengedepankan kelebihan lain yang tidak dimiliki oleh pesaing dan kompetitornya. Menurut Martha dkk (2012) Indonesia merupakan salah satu eksportir kayu dan furnitur terbesar di dunia. Namun secara kualitas produk Indonesia masih kalah bersaing dengan produk dari negara lain. Rendahnya penguasaan teknologi proses manufakturing dan pemahaman sifat mekanik pada kayu menjadi salah satu penyebabnya. Pemakaian bahan baku dan pengerjaan kayu yang tidak sesuai dengan standar spesifikasi dan jenis kayu membuat produk yang dihasilkan memiliki kualitas yang kurang baik.

Penerapan Standar Nasional Indonesia (SNI) merupakan strategi penting Pemerintah untuk meningkatkan daya saing industri kecil menengah. SNI perlu didorong karena terkait dengan tersedianya produk industri yang memenuhi sejumlah standar, seperti keamanan dan kenyamanan. SNI mengamankan pasar domestik dari serbuan produk negara lain yang di bawah standar. Standardisasi secara umum merupakan rangkaian proses mulai dari pengembangan standar (pemrograman, perumusan, penetapan dan pemeliharaan standar) dan penerapan standar yang dilaksanakan secara tertib dan bekerja sama dengan para pemangku kepentingan (BSN, 2010).

Di dalam standardisasi standar nasional suatu negara umumnya dirancang mengacu ke standar internasional misalnya mengacu kepada standar internasional IEC atau ISO, ketika suatu national differences dicantumkan dalam standar nasional maka standar nasional tersebut menjadi standar nasional dengan national differences terhadap standar internasional. National differences memang dimungkinkan bila standar internasional yang ada akan menjadi cara yang tidak efektif atau tidak sesuai dalam memenuhi tujuan yang sebenarnya dari suatu regulasi yang dapat disebabkan oleh berbagai hal, antara lain faktor iklim dan geografis yang mendasar atau alasan teknologi yang mendasar.

Penelitian ini bertujuan untuk mengetahui aspek yang belum ada dalam SNI produk furnitur dari kayu yang dapat kembangkan untuk meningkatkan daya saing industri furnitur, selain untuk mendorong peningkatan ekspor juga untuk melindungi pasar domestik.

\section{TINJAUAN PUSTAKA}

\subsection{Furnitur dari Kayu}

Furnitur adalah istilah yang digunakan untuk perabot rumah tangga yang berfungsi sebagai tempat penyimpan barang, tempat duduk, tempat tidur, tempat mengerjakan sesuatu dalam bentuk meja atau tempat menaruh barang di permukaannya. Furniture dalam bahasa Indonesia juga diterjemahkan sebagai mebel, istilah mebel digunakan karena sifat bergeraknya atau mobilitasnya sebagai barang lepas di dalam interior arsitektual (Bertaria dkk, 2016). Furnitur dapat dibuat dari berbagai bahan, seperti logam, plastik, kayu, bahan berbasis kayu, rotan, bambu, atau kombinasinya.

Proses produksi ditentukan oleh jenis material yang digunakan dan skala produksi. Untuk furnitur kayu, bahan utamanya menggunakan balok kayu yang berasal dari satu atau lebih jenis kayu yang sesuai untuk pengolahan kayu atau panel dari kayu. Balok 
kayu lembut berasal dari kelompok pohon berdaun jarum (konifer). Pohon ini cepat bertumbuh dengan pola serat yang longgar. Kayu pohon ini mudah diukir dan diolah. Karena permukaannya yang lembut, pohon ini rentan mengalami kerusakan pada permukaannya. Di sisi lain, balok kayu keras dari pohon berdaun lebar (termasuk kayu keras tropis seperti kayu mahoni, jati, dan ipe) umumnya dianggap sebagai material konstruksi perabotan yang lebih baik karena kekuatan kayunya, namun sulit untuk diukir atau diolah.

Bahan baku kayu harus dikeringkan sebelum digunakan untuk produksi. Tempat pengeringan (dry clean) merupakan oven besar, dimana kayu diawetkan melalui pengendalian panas dan kelembapan secara hati-hati, untuk menghilangkan 93\% kandungan air dari kayu. Kayu yang belum dikeringkan melalui dry clean akan mudah melingkar, terpecah dan retak, sehingga menyebabkan kualitas yang rendah pada furnitur pengguna akhir. Kayu mentah dalam bentuk batang kayu dipotong menjadi lingkaran besar atau digergaji melingkar menjadi papan, yang lalu diproses melalui proses produksi pembuatan kayu termasuk menggergaji (sawing), diukir sesuai poros (spindle), tenoning, perekatan (glueing), perawatan permukaan, lacqueing, dan sesuai kebutuhan, dirakit dengan perangkat keras.

Furnitur kayu dapat mencakup kayu padat atau kayu olahan (panel) atau kombinasi keduanya. Kebanyakan kayu olahan digunakan dalam bentuk kayu lapis (plywood) dan papan serat (fiber board) (terutama MDF yang banyak digunakan) dengan lapisan buatan (terbuat dari plastik, kertas timah, kertas dan dicetak dengan pola yang diinginkan) atau lapisan veener (lembaran tipis dengan kualitas kayu yang lebih baik mendekorasi dasar kayu yang lebih murah). Pengolahan dan produksi furnitur rotan berbeda dengan pengolahan furnitur kayu klasik. Bambu dijual dalam bentuk lembaran dan papan dan juga digunakan pada pekerjaan konstruksi. Popularitas bambu dan rotan meningkat pada tahun-tahun terakhir karena asal-usul ekologisnya. Namun, pada saat pembuatannya, diperlukan perawatan untuk memastikan kekuatan yang memadai pada produk akhir.

\subsection{Faktor yang Mempengaruhi Furnitur 2.2.1 Mutu Bahan Baku}

Pembuatan furnitur kayu pada dasarnya tergantung jenis dan mutu dari kayu olahan yang dipergunakan, terpenting dalam pembuatan furnitur kayu tersebut harus memenuhi beberapa persyaratan antara lain sebagai berikut : Bahan baku kayu tidak mempunyai cacat atau tanda potongan dari cabang-cabang yang bisa mengurangi kualitas. Kayu yang kena serangga, jamur atau bakteri tidak boleh dipergunakan ujung-ujung atau sisi-sisi dari bagian-bagian suatu furnitur yang menonjol harus ditumpulkan agar tidak membahayakan bagi pemakai. Adanya cacat pada permukaan kayu akibat proses permesinan yang kurang tepat akan menambah jumlah proses finishing yang harus dilakukan (Rusnaldy dkk, 2009).

Dalam memproduksi furnitur perlu memperhatikan mutu bahan baku, proses produksi misalnya, dengan melakukan pengeringan kayu dengan alat pengering atau dijemur sehingga menghasilkan kayu yang tidak mudah kena jamur, dan tidak mudah berubah bentuk atau ukuran sampai siap untuk dijual. Pada tahap finishing diperlukan ketelitian dan kerapian dalam membuat suatu produk sampai siap untuk dijual, sehingga produk tersebut mempunyai mutu yang tinggi, yang pada akhirnya mempunyai nilai jual yang tinggi. Adapun kandungan air yang ada dalam kayu sebagai bahan mebel juga harus diperhatikan, karena hal ini sangat berpengaruh terhadap kualitas/mutu produk furnitur yang dapat menimbulkan pengembangan/penyusutan yang tidak teratur, retak-retak/pecah, bengkok/melengkung dan melintir.

Apabila furnitur tersebut ditempatkan pada kondisi kandungan udara dengan perubahan iklim udara yang cukup tinggi perlu disesuaikan dengan kondisi kayu melalui pengurangan kadar air. Untuk produk furnitur kayu kadar air yang aman adalah 0-12 \%. Pengurangan kadar air bahan mebel dapat dilakukan melalui proses pengeringan/ pengovenan.

\subsubsection{Serangga Perusak Furnitur Kayu}

Rayap dikelompokan lagi menjadi rayap penghuni tanah atau rayap penghuni kayu; rayap penghuni kayu tidak membentuk sarang, tetapi hidup pada lubang-lubang dalam kayu pohon di daerah hutan tropik (Handayanto \& Hairiah, 2009). Rayap berkembang biak sangat cepat dan dalam jumlah banyak. Perbedaan ini disebabkan adanya keragaman yang cukup tinggi dalam dunia, jumlahnya hampir mencapai 3.000 spesies dan penyebarannya yang cukup luas (Prasetyo \& Yusuf, 2005).

Di Indonesia sendiri terdapat kurang dari 200 spesies, 179 spesies telah berhasil diidentifikasi, yaitu 4 jenis rayap kayu kering, 166 jenis rayap kayu basah, dan 9 jenis rayap tanah (subterannean). Sekitar 20 spesies yang diketahui berperan sebagai hama perusak kayu serta hama pertanian. Di daerah tropis terutama 
di Indonesia, rayap tanah (coptotermes curvignathus holmgren) merupakan salah satu serangga yang paling banyak menimbulkan kerusakan pada kayu dan bangunan kayu (Gambar 1 dan Gambar 2).

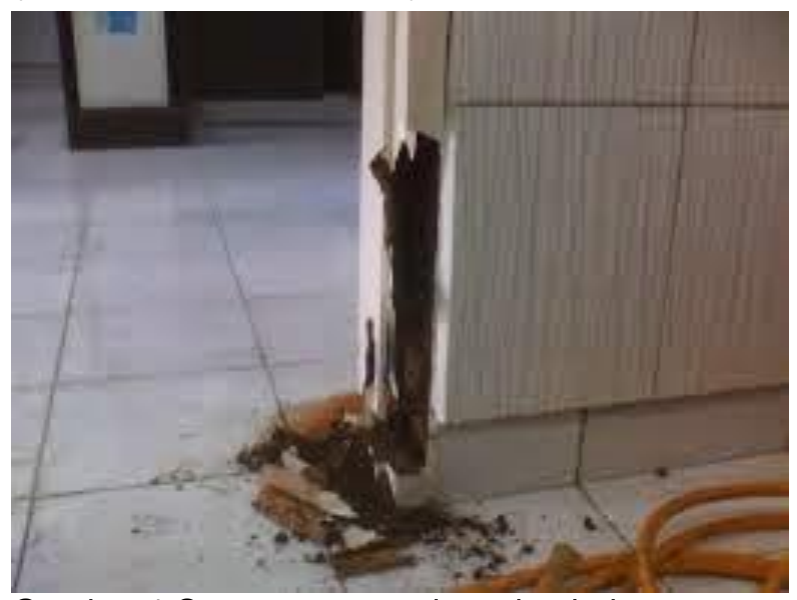

Gambar 1 Serangan rayap kayu lembab.

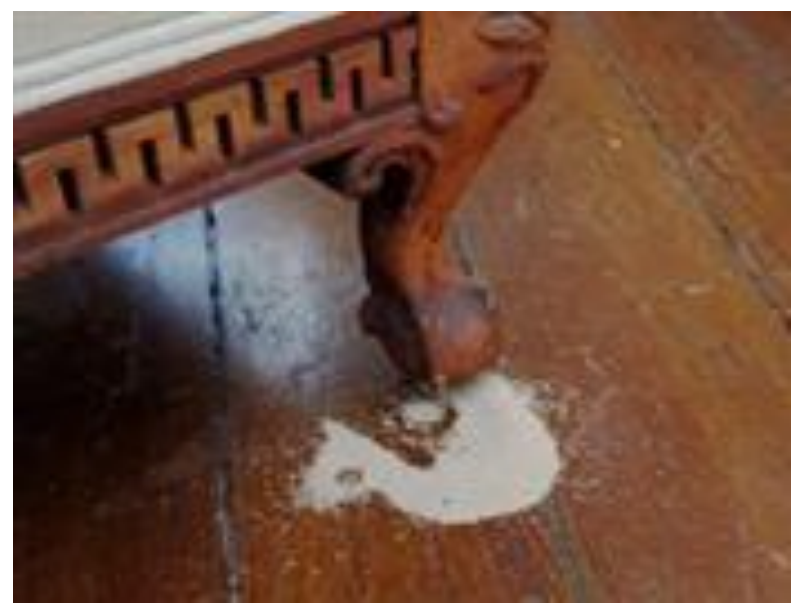

Gambar 2 Serangan rayap kayu kering.

Indonesia adalah surga bagi rayap. Di mana iklim Indonesia memiliki suhu udara yang hangat namun memiliki kelembaban udara yang tinggi. Rayap merupakan salah satu jenis serangga perusak perabotan rumah atau furnitur yang terbuat dari kayu. Selain pendapat diatas, Susanta (2007) juga memberikan penggolongan rayap dengan cirinya sebagai berikut :

- Rayap kayu lembap (damp wood termite), Rayap kayu lembap menyerang kayu mati dan lembap. Rayap ini bersarang dalam, tetapi tidak berhubungan dengan tanah. Adapun beberapa cirinya antara lain : serangan pada kayu basah atau lembap atau pohon mati yang membusuk; sarang berada dalam kayu yang membusuk atau basah seperti tonggaktonggak kayu atau kayu gelondongan; ukuran tubuh rayap prajurit 2,5 kali lebih besar dari rayap tanah; populasi lebih kecil dari rayap tanah, tidak mempunyai kasta pekerja sehingga tugas pekerja dilakukan oleh nimfa, dan ukuran palet lebih besar dan berwarna gelap,

- Rayap kayu kering (dry wood termite), Rayap kayu kering hidup dalam kayu mati yang telah kering. Hama ini umumnya dapat dijumpai di rumah-rumah. Terutama pada perabot-perabot seperti lemari, meja, kursi dan sebagainya. Seperti halnya rayap kayu lembap, rayap ini pun tidak berhubungan dengan tanah karena habitatnya kering. Rayap kayu kering dapat hidup dapat hidup dalam kayu dengan kandungan air 5-6\%. Adapun ciri-ciri yang dimiliki oleh rayap ini antara lain : serangannya terhadap kayu-kayu kering pada bangunan, furnitur, dan lain-lain; tanda serangannya adanya butir-butir kecil berwarna kecoklatan yang sering berjatuhan di lantai atau kayu yang diserang; tidak berhubungan dengan tanah karena habitatnya di dalam kayu kering, dan jumlah populasi dalam satu koloni lebih sedikit dibanding rayap tanah.

\subsection{SNI dan National Differences dalam Standar}

Standar Nasional Indonesia (SNI) adalah standar yang ditetapkan oleh Badan Standardisasi Nasional dan berlaku secara nasional (PP 102, 2000). Standardisasi secara umum merupakan rangkaian proses mulai dari pengembangan standar (pemrograman, perumusan, penetapan dan pemeliharaan standar) dan penerapan standar yang dilaksanakan secara tertib dan bekerja sama dengan para pemangku kepentingan (UU SPK, 2014). SNI pada dasarnya adalah bersifat voluntary (sukarela). Namun apabila standar tersebut menyangkut kepentingan keselamatan, keamanan, kesehatan dan kelestarian fungsi lingkungan hidup, maka penerapannya diberlakukan secara wajib oleh instansi teknis (PP 102 Tahun 2000).

National differences (ND) secara harfiah dapat diartikan kekhasan atau karakterteristik unik yang dimiliki oleh suatu negara yang menyebabkan sesuatu yang dimiliki oleh negara tersebut menjadi berbeda dengan yang dimiliki oleh kebanyakan negara lain (Wibowo \& Pribadi, 2015). Sifat yang khas ini dapat bersumber dari berbagai aspek kehidupan, kondisi suatu negara, kultur/budaya, agama, sifat dari pemerintahan dan lain lain. National differences dalam standar yang terkadang juga disebut national deviation adalah perbedaan standar nasional suatu negara terhadap standar internasional yang harus dicantumkan dalam standar nasional. Perbedaan atau penyimpangan teknis tersebut dilakukan dengan cara modifikasi standar, yaitu dengan mengubah atau menambahkan persyaratan 
tertentu dalam standar nasional terhadap standar internasional. Standar nasional suatu negara umumnya dirancang mengacu ke standar internasional misalnya mengacu kepada standar internasional IEC atau ISO, ketika suatu national differences dicantumkan dalam standar nasional maka standar nasional tersebut menjadi standar nasional dengan national differences terhadap standar internasional.

Dalam standardisasi, national differences dimungkinkan bila standar internasional yang ada akan menjadi cara yang tidak efektif atau tidak sesuai dalam memenuhi tujuan yang sebenarnya dari suatu regulasi yang dapat disebabkan oleh berbagai hal, antara lain faktor iklim dan geografis yang mendasar atau alasan teknologi yang mendasar. Dalam hal penilaian kesesuaian, selanjutnya alasan untuk beda dengan international best practice antara lain dikarenakan oleh alasan keamanan nasional, mencegah praktek pengelabuan/kecurangan, serta perlindungan kesehatan dan keselamatan manusia, kesehatan dan kehidupan hewan dan tanaman, atau alasan lain seperti yang disebutkan dalam perjanjian Technical Barrier To Trade (TBT) WTO: "Where technical regulations are required and relevant international standards exist or their completion is imminent, Members shall use them, or the relevant parts of them, as a basis for their technical regulations except when such international standards or relevant parts would be an ineffective or inappropriate means for the fulfilment of the legitimate objectives pursued, for instance because of fundamental climatic or geographical factors or fundamental technological problems" (TBT Agreement article 2.4).

\subsection{Daya Saing}

Vukovic dkk (2012) mengatakan bahwa daya saing (competitiveness) memiliki beberapa definisi dan teori. World Economic Forum 2014 mendefinisikan daya saing sebagai seperangkat institusi, kebijakan, dan faktor yang menentukan tingkat produktivitas suatu negara. Tingkat produktivitas akan menentukan tingkat kemakmuran yang dapat dicapai dengan ekonomi. Tingkat produktivitas juga menentukan tingkat pengembalian investasi dalam perekonomian, yang akan menjadi pendorong utama tingkat pertumbuhan. Dengan kata lain, ekonomi yang lebih kompetitif kemungkinan akan tumbuh lebih cepat dari waktu ke waktu. Sementara menurut Porter (2006), daya saing adalah fondasi kemakmuran, berdasarkan potensi produktif perekonomian suatu negara, yang pada gilirannya akhirnya ditetapkan oleh produktivitas perusahaan yang ditentukan oleh kecanggihan operasi dan strategi perusahaan serta kualitas lingkungan bisnis ekonomi mikro.

\section{METODE PENELITIAN}

Dalam penelitian ini data diperoleh melalui studi pustaka Standar Nasional Indonesia (SNI) terkait kayu dan furnitur (2000-2017), Standar ISO, Regulasi Europe Union (EU), Data Ekspor Impor Produk Furnitur Indonesia. Sedangkan data primer potensi national differences di dapat melalui survei lapangan wawancara mendalam dan melalui Focus Gorup Discussion (FGD) dengan para narasumber yang merupakan expert (praktisi dan peneliti) yang memahami dalam hal standardisasi.

Data primer dan sekunder diolah menggunakan analisa kualitatif deskriptif, yang merupakan suatu teknik yang menggambarkan dan menginterpretasikan data-data dengan memberikan perhatian dan merekam sebanyak mungkin aspek situasi yang diteliti sehingga memberikan gambaran umum dan menyeluruh tentang keadaan sebenarnya (Moleong, 2008).

\section{HASIL DAN PEMBAHASAN}

\subsection{Ekspor Impor Industri Furnitur Indonesia}

Industri furnitur nasional memiliki potensi besar berkembang dengan dukungan sumber bahan baku yang melimpah dan perajin yang memprioritaskan sektor padat karya, Menurut Indrawan (2014). Uni Eropa merupakan pasar terbesar ekspor furnitur dan kerajinan asal Indonesia, yakni 40 persen. Peringkat pasar ekspor kedua Amerika Serikat sebesar 29 persen dan Jepang 12 persen.

Berdasarkan data ekspor impor industri furnitur Indonesia yang diolah dari Kementerian Perindustrian (2016), ekspor produk furnitur Indonesia masih lebih besar (surplus) dari impor (Tabel 1 dan Tabel 2, diolah).

Tabel 1 Ekspor produk furnitur indonesia tahun 2012- 2016.

\begin{tabular}{cc} 
Tahun & $\begin{array}{c}\text { Nilai } \\
\text { (dalam Ribu US Dollar) }\end{array}$ \\
2012 & $1.749 .703,10$ \\
2013 & $1.718 .827,60$ \\
2014 & $1.767 .146,00$ \\
2015 & $1.713 .876,90$ \\
2016 & $1.617 .746,00$ \\
\hline
\end{tabular}




\section{Grafik Ekspor Furnitur}

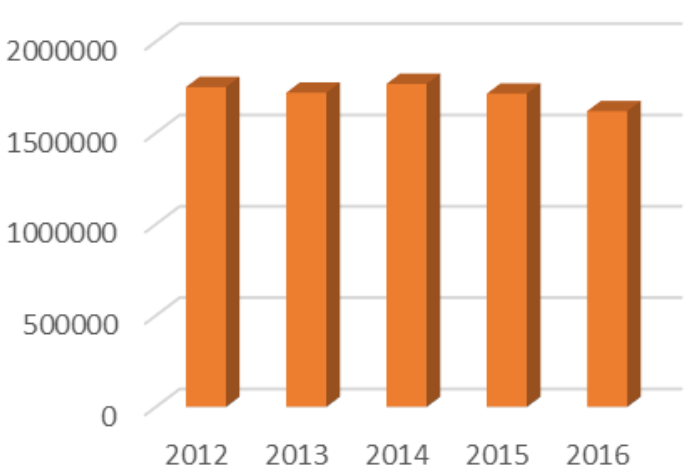

Grafik 1 Ekspor produk furnitur indonesia tahun 2012- 2016.

Tabel 2 Impor produk furnitur indonesia tahun 2012- 2016.

\begin{tabular}{cc}
\hline Tahun & $\begin{array}{c}\text { Nilai } \\
\text { (dalam Ribu US Dollar) }\end{array}$ \\
\hline 2012 & $773.585,20$ \\
2013 & $767.507,90$ \\
2014 & $718.122,80$ \\
2015 & $662.547,80$ \\
2016 & $639.344,90$ \\
\hline
\end{tabular}

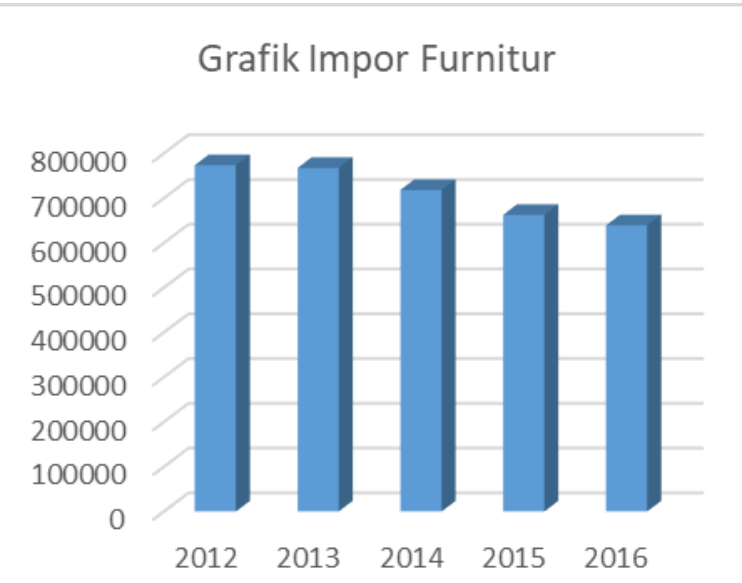

Grafik 2 Ekspor produk furnitur indonesia tahun 2012- 2016.

Dari data ekspor produk furnitur diketahui bahwa nilai ekspor Indonesia dalam 5 tahun terakhir walaupun relatif stabil namun terjadi trend penurunan sebesar $1,58 \%$, Sedangkan data impor produk furnitur diketahui bahwa nilai impor Indonesia dalam 5 tahun terakhir mempunyai trend penurunan sebesar $5,11 \%$, namun perlu diwaspadai mengingat nilainya sekitar $45 \%$ dari total ekspor Indonesia. Hal ini dapat di artikan perlunya pengembangan di bidang desain, teknik produksi, serta proses pengemasan dan penyelesaian produk yang bersifat fashionable dan lifestyle, yang masuk kategori industri kreatif, sehingga dengan inovasi dan kreativitas menjadi kunci keberlangsungan produk furnitur.

Suwita (2016) menyebutkan bahwa daya saing furnitur Indonesia memiliki daya saing yang tinggi di pasar Uni Eropa, untuk meningkatkan export furniture Indonesia ke pasar Uni Eropa, pembuat kebijakan dapat membuat suatu program yang dapat menunjang industri furnitur, terutama bagi industri kecil dan menengah sehingga dapat meningkatkan kualitas dan rancangan dari produknya. Pembuat kebijakan juga dapat memberikan informasi kepada produsen furnitur terkait regulasi, standard dan kondisi pasar Uni Eropa. Hal lain yang dapat dilakukan adalah melakukan kerjasama dengan institusi keuangan maupun laboratorium milik pemerintah dalam menyediakan bantuan keuangan atau skema pembayaran untuk sertifikasi produk yang tidak memberatkan bagi industry kecil dan menengah.

Adapun Komoditi yang umumnya di ekspor impor ke Indonesia, seperti yang disajikan pada Tabel 3 dan Tabel 4 (Kementerian Perindustrian, 2017, diolah).

Tabel 3 komoditi impor produk furnitur indonesia berdasarkan kode HS.

\begin{tabular}{ccl}
\hline No & Kode HS & \multicolumn{1}{c}{ Komoditi } \\
\hline 1 & 9401400000 & $\begin{array}{l}\text { Seats oth than garden seats/ } \\
\text { equepment, } \\
\text { comvertible into beds }\end{array}$ \\
\hline 2 & 940159.000 & $\begin{array}{l}\text { Seat of cane,osier or similar } \\
\text { material }\end{array}$ \\
\hline 3 & 9401510010 & Seat of rattan \\
\hline 4 & 9401510020 & Seat of bamboo \\
\hline 5 & 9401610000 & $\begin{array}{l}\text { Oth seats, with wooden } \\
\text { frames, upholstered }\end{array}$ \\
\hline 6 & 9401690010 & $\begin{array}{l}\text { Oth seats, with wooden } \\
\text { frames, combined with rattan }\end{array}$ \\
\hline 7 & 9401690090 & $\begin{array}{l}\text { Oth seats, with wooden } \\
\text { frames,combined with other } \\
\text { than rattan }\end{array}$ \\
\hline 8 & 9401800000 & $\begin{array}{l}\text { Oth seats(oth than those of } \\
\text { head 9402) }\end{array}$ \\
\hline 9 & 9401901000 & $\begin{array}{l}\text { Parts of aircraft seats (head } \\
\text { 94011000) }\end{array}$ \\
\hline
\end{tabular}




\begin{tabular}{|c|c|c|}
\hline No & Kode HS & Komoditi \\
\hline 10 & 9401903900 & Parts of other seats \\
\hline 11 & 9401903100 & $\begin{array}{l}\text { headrest stiffeners for seats } \\
\text { of subheading } 94012010 \text {, }\end{array}$ \\
\hline 12 & 9401904000 & $\begin{array}{l}\text { Parts of seats of subheading } \\
94013000\end{array}$ \\
\hline 13 & 9401909900 & $\begin{array}{l}\text { Parts of seats of other than } \\
\text { plastics }\end{array}$ \\
\hline 14 & 9403810010 & $\begin{array}{l}\text { Bedroom, dining room or } \\
\text { living room sets of rattan }\end{array}$ \\
\hline 15 & 9403810020 & $\begin{array}{l}\text { Bedroom, dining room or } \\
\text { living room sets of bamboo }\end{array}$ \\
\hline 16 & 9403300000 & $\begin{array}{l}\text { Wooden furniture of a kind } \\
\text { used in offices }\end{array}$ \\
\hline 17 & 9403400000 & $\begin{array}{l}\text { Wooden furniture of a kind } \\
\text { used in the kitchen }\end{array}$ \\
\hline 18 & 9403500000 & $\begin{array}{l}\text { Wooden furniture of a kind } \\
\text { used in the bedroom }\end{array}$ \\
\hline 19 & 9403601000 & $\begin{array}{l}\text { Oth wooden furniture,fume } \\
\text { cupboard }\end{array}$ \\
\hline 20 & 9403609000 & $\begin{array}{l}\text { Oth wooden furniture,oth than } \\
\text { fume cupboard }\end{array}$ \\
\hline 21 & 9403810030 & $\begin{array}{l}\text { Furniture,of kind used in } \\
\text { parks gardens/vestibules of } \\
\text { rattan/bamboo }\end{array}$ \\
\hline 22 & 9403810090 & $\begin{array}{l}\text { Other furniture of bamboo or } \\
\text { rattan }\end{array}$ \\
\hline 23 & 9403899090 & $\begin{array}{l}\text { Other furniture of cane, osier, } \\
\text { bamboo or similar materials }\end{array}$ \\
\hline 24 & 9403891000 & $\begin{array}{l}\text { Other furniture of other } \\
\text { materials, fume cupboards }\end{array}$ \\
\hline 25 & 9403899010 & $\begin{array}{l}\text { Bedroom, dining room/living } \\
\text { room sets of other materials }\end{array}$ \\
\hline 26 & 9403899020 & $\begin{array}{l}\text { Oth furniture of a kind used in } \\
\text { parks, garden/vestibules of } \\
\text { oth materials }\end{array}$ \\
\hline 27 & 9404100000 & Mattress supports \\
\hline 28 & 9404210000 & $\begin{array}{l}\text { Mattresses of cellular rubber } \\
\text { or plastics, whether or not } \\
\text { covered }\end{array}$ \\
\hline 29 & 9404291000 & $\begin{array}{l}\text { Mattress springs of other } \\
\text { materials }\end{array}$ \\
\hline 30 & 9404292000 & $\begin{array}{l}\text { Mattress of hyperthermia or } \\
\text { hyphothermia type of oth } \\
\text { materials }\end{array}$ \\
\hline 31 & 9404299000 & Mattress of other materials \\
\hline
\end{tabular}

Tabel 4 Komoditi Ekspor Produk Furnitur, Industri Kayu berdasarkan Kode HS.

\begin{tabular}{|c|c|c|}
\hline No & Kode HS & Komoditi \\
\hline 1. & 9401690090 & $\begin{array}{l}\text { Oth seats, with wooden } \\
\text { frames,combined with other } \\
\text { than rattan }\end{array}$ \\
\hline 2. & 9403500000 & $\begin{array}{l}\text { Wooden furniture of a kind used } \\
\text { in the bedroom }\end{array}$ \\
\hline 3. & 9403400000 & $\begin{array}{l}\text { Wooden furniture of a kind used } \\
\text { in the kitchen }\end{array}$ \\
\hline 4. & 9403300000 & $\begin{array}{l}\text { Wooden furniture of a kind used } \\
\text { in offices }\end{array}$ \\
\hline 5. & 9401690010 & $\begin{array}{l}\text { Oth seats, with wooden } \\
\text { frames,combined with rattan }\end{array}$ \\
\hline 6. & 9401800000 & $\begin{array}{l}\text { Oth seats(oth than those of } \\
\text { head 9402) }\end{array}$ \\
\hline 7. & 9401610000 & $\begin{array}{l}\text { Oth seats, with wooden } \\
\text { frames, upholstered }\end{array}$ \\
\hline 8. & 9403601000 & $\begin{array}{l}\text { Oth wooden furniture, fume } \\
\text { cupboard }\end{array}$ \\
\hline 9. & 9401400000 & $\begin{array}{l}\text { Seats oth than garden seats/ } \\
\text { camping } \\
\text { equepment,comvertible into } \\
\text { beds }\end{array}$ \\
\hline
\end{tabular}

\section{a. SNI dan Komite Teknis Perumusan SNI Produk Furnitur}

Pengertian standar adalah dokumen tertulis yang berisi aturan, pedoman, atau karakteristik suatu barang dan/jasa atau proses dan metode yang berlaku umum dan digunakan secara berulang. Penyusunan standar pada prinsipnya didasarkan atas kebutuhan dan hasil konsensus para pemangku kepentingan untuk mencapai keteraturan dalam berbagai aspek ekonomi, sosial, lingkungan guna menunjang pembangunan berkelanjutan (BSN, 2010).

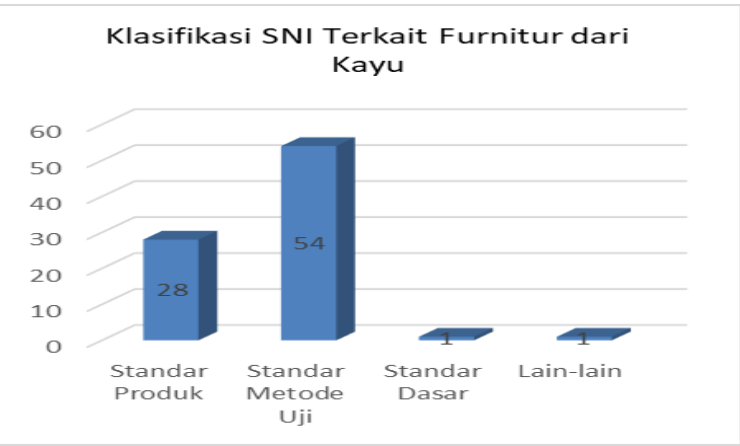

Grafik 3 SNI terkait furnitur.

Dalam penelitian ini standar di klasifikasikan menjadi: standar produk, standar pengujian, standar sistem, standar dasar dan standar lain-lain. Hasil identifikasi melalui Sistem 
Informasi SNI, 2016 diperoleh hasil identifikasi SNI terkait produk furnitur yang terbuat dari produk hasil hutan pada Grafik 3.

Komite Teknis yang merumuskan SNI produk furnitur adalah Komite Teknis 9702 Furnitur yang sekretariatnya berada di Kementerian Perindustrian.

\section{b. National Differences dalam SNI Furnitur}

Rayap banyak dijumpai menyerang peralatan mebel seperti meja, lemari dan lain-lain. Rayap adalah salah satu faktor yang mempercepat kerusakan pada furnitur yang terbuat dari kayu. Daerah tropis seperti Indonesia, penurunan kualitas bahan bangunan didorong oleh kondisi iklim yang lembab, curah hujan dan suhu yang tinggi serta oleh tingginya kelimpahan faktor perusak biologis seperti rayap dan jamur, di Indonesia diperkirakan kerusakan bagunan sebagian besar diakibatkan faktor perusak bangunan yang kurang begitu diperhatikan, yaitu air dan makhluk hidup seperti: rayap dan jamur (Aini, 2005).

Di dalam standardisasi, national differences dimungkinkan bila standar internasional yang ada akan menjadi cara yang tidak efektif atau tidak sesuai dalam memenuhi tujuan yang sebenarnya dari suatu regulasi yang dapat disebabkan oleh berbagai hal, antara lain faktor iklim dan geografis yang mendasar atau alasan teknologi yang mendasar. Disisi lain Indonesia adalah surga bagi rayap. Di mana iklim Indonesia memiliki suhu udara yang hangat namun memiliki kelembaban udara yang tinggi. Hal ini sangat sesuai untuk perkembangbiakan rayap, sebanyak 200 jenis rayap tanah di Indonesia. Dari sebanyak itu, lima persennya menjadi musuh manusia. $\mathrm{Di}$ daerah tropis terutama di Indonesia, rayap tanah (coptotermes curvignathus holmgren) merupakan salah satu serangga yang paling banyak menimbulkan kerusakan pada kayu dan bangunan kayu.

$\mathrm{Di}$ Eropa misalnya diberlakukan peraturan untuk produk furnitur yang mengatur mengenai keselamatan produk, misalnya General Product Safety Directive 2001/95/EC, yang mensyaratkan bahwa hanya produk yang aman yang dapat dipasarkan di Uni Eropa. GPSD bertujuan untuk memastikan tingkat keamanan produk yang tinggi di seluruh Uni Eropa untuk produk konsumen. Peraturan tersebut menentukan apa saja yang dapat disebut sebagai produk yang aman, yaitu produk apapun yang dalam kondisi penggunaan wajar yang dapat diperkirakan tidak memberikan risiko atau memiliki tingkat risiko yang dapat diterima, serta konsisten dengan tingkat perlindungan keselamatan konsumen yang tinggi. Terdapat beberapa hal khusus yang harus dipertimbangkan:

1) Karakteristik produk, termasuk komposisi, pengemasan, instruksi perakitan, dan jika ada, instruksi untuk instalasi dan perawatan.

2) Efek produk tersebut terhadap produk lain, dalam kondisi yang dapat diperkirakan, untuk penggunaan bersama dengan produk lain.

3) Tampilan produk, pelabelan, peringatan dan instruksi mengenai penggunaan dan pembuangan, serta indikasi atau informasi lain mengenai produk.

4) Kategori konsumen yang berisiko ketika menggunakan produk, khususnya anak-anak dan orang lansia.

Selain hal tersebut, dalam Decision 2009/251/EC on DMF terdapat keputusan khusus yang melarang penggunaan dimethylfumarate (DMF) yaitu zat yang digunakan sebagai bahan anti jamur, pada perabotan berlapis kain (upholstery). Dari standar internasional ISO dan standar Eropa tersebut diketahui beberapa uji yang penting dilakukan untuk mengatahui kualitas dari produk furnitur beberapa hal yang diujikan dari standar diantaranya berdasarkan :

a. Kelas penggunaan (rumah tangga, komersial, di luar ruangan) dan tujuan penggunaan

b. Jenis material dan struktur furnitur:
1) Material dasar (termasuk lapisan pendukung, lapisan akhir)
2) Lapisan kain / upholstery (jika ada)
3) Cat dan pernis yang digunakan
4) Komponen perangkat keras yang digunakan

c. Geometri dan ergonomika

d. Stabilitas

e. Keselamatan (dari bahaya mekanis)

f. Daya tahan mekanis

g. Klasifikasi lapisan permukaaan perabotan:
1) Daya tahan panas kering (dry heat)
2) Daya tahan panas lembap (moist heat)
3) Daya tahan cairan dingin (cold liquids)
4) Daya tahan abrasi
5) Daya tahan gores

h. Pantulan cahaya/kilauan permukaan

i. Daya tahan terhadap pelapukan biologis

j. Keterbakaran

k. Emisi formaldehida, pentachlorophenol dan VOC

I. Lain-lain (jenis perabotan yang terkait dengan karakteristik khusus). 
(sumber : Kemendag.go.id, 2013).

Berdasarkan faktor tersebut di atas dan hasil Forum Grup Discussion (FGD) dengan peneliti serangga dan anggota Komite Teknis, beberapa hal yang berpotensi untuk dikembangkan sebagai national differences untuk produk furnitur yang terbuat dari kayu adalah :

\section{Uji Ktahanan Rayap}

Rayap merupakan hama yang merusak produk kayu secara umum. Rayap bersarang pada kayu dan memakan kayu pada produk furnitur. Rayap daerah tropis umumnya memiliki karakter lingkungan hidup yang lembab. Kondisi lingkungan yang lembab merupakan kondisi lingkungan yang terdapat di Indonesia.

\section{Uji Hama Bubuk Kayu}

Bubuk kayu merupakan jenis kumbang yang makan kayu seperti meja kursi, buffet atau barang lainnya dalam rumah yang terbuat dari kayu atau produk kayu. Bubuk kayu sangat menyukai kelembaban yang tinggi dan kondisi tersebut adalah kondisi Indonesia sepanjang tahun. Bubuk kayu di Indonesia berbeda dengan bubuk kayu dari negara subtropis. Bubuk kayu kering di Indonesia lebih banyak variasi dan lebih ganas dibanding dari negara subtropis karena keadaan suhu dan kelembaban yang sangat cocok di Indonesia yang tidak sama dengan negara subtropis.

\section{Uji Ketahanan Jamur}

Iklim Indonesia yang suhunya panas dan kelembaban tinggi. Misalnya di Jakarta suhu $26-$ $32{ }^{\circ} \mathrm{C}$ dan kelembaban 60 - 96\% (BMKG, 2017). Suhu tinggi dan kelembaban tinggi merupakan kondisi yang optimum untuk kehidupan jamur pada produk-produk kayu khususnya produk furnitur dan kondisi tersebut berbeda dengan negara subtropis. Jamur yang sering menyerang produk furnitur yaitu jenis jamur blue stain.

\section{Uji Kestabilan Dimensi}

Umumnya yang berpengaruh pada kestabilan kayu adalah kandungan air pada kayu, namun negara lain seperti Amerika menggunakan zat tertentu agar kestabilan dimensi tidak berubah walaupun kadar air berubah drastis.

\section{Uji kadar Air}

Tidak ada perbedaan antara produk impor maupun produk dalam negeri. Kadar air merupakan faktor yang bisa dibuat selama kita menguasai metode dan teknologinya. Artinya jika kadar air kayu untuk digunakan di Indonesia sekitar $15-20 \%$, maka produsen di luar negeri pun mampu membuat furnitur dengan kadar air sesuai kebutuhan di Indonesia. Ini bukan menjadi faktor penghambat produk impor untuk masuk
Indonesia namun jelas bahwa produk furnitur yang dapat didistribusikan sesuai dengan ketentuan tingkat kadar air. Begitu pula produk Indonesia untuk diekspor.

\section{KESIMPULAN}

Trend ekspor produk furnitur selama 5 tahun terakhir (2012-2016) menurun 1,58\%. Sedangkan trend impor juga mengalami penurunan sebesar $5,11 \%$, namun secara volume nilai impor produk furnitur masih cukup besar yaitu $40 \%-45 \%$ dari nilai produk ekspor.

Perlunya pengembangan di bidang desain, teknik produksi, serta proses pengemasan dan penyelesaian produk yang bersifat fashionable dan lifestyle, yang masuk kategori industri kreatif, sehingga dengan inovasi dan kreativitas menjadi kunci keberlangsungan produk furnitur.

Iklim Indonesia memiliki suhu udara yang hangat namun memiliki kelembaban udara yang tinggi bagi rayap. Faktor iklim Indonesia (negara tropis) dapat menjadi faktor national differences bagi pengembangan SNI, rayap, jamur dan bubuk kayu di Indonesia memiliki variasi dibanding negara subtropis, sehingga Uji ketahanan rayap, Uji hama bubuk kayu, Uji ketahanan jamur dapat dikembangkan dalam SNI produk furnitur dari kayu. Saat ini terdapat 35 SNI produk furnitur yang terdiri SNI produk (88\%), metode uji (8\%) dan terminologi (3\%).

\section{UCAPAN TERIMA KASIH}

Penulis mengucapkan puji syukur kepada Allah SWT yang telah memberikan rahmat Nya sehingga dapat menyelesaikan penelitian ini, juga mengucapkan terima kasih kepada Kepala Pusat Penelitian dan Pengembangan Standardisasi (Puslitbang), Para Peneliti Bidang Standardisasi, Peneliti tentang serangga serta rekan-rekan yang telah banyak memberikan masukan dan pandangan terhadap materi penelitian ini.

\section{DAFTAR PUSTAKA}

Aini N. (2005). Perlindungan Investasi Konstruksi Terhadap Serangan Organisme Perusak. Pusat Penelitian dan Pengembangan Permukiman Badan Penelitian dan Pengembangan Pekerjaan Umum. Bandung

Arief, A. (2001). Hutan dan Kehutanan. Kanisius. Yogyakarta. 
Wibowo, Ari dan Teguh Pribadi. (2015). Kebutuhan National Differences dalam SNI Tusuk Kontak dan Kotak Kontak. Jurnal Standardisasi Vo.17 No.1 Tahun 2015. 67-74.

Badan Standardisasi Nasional. (2010) SNI Penguat Daya Saing Bangsa. Jakarta : BSN

Badan Standardisasi Nasional (2016), Sistem Informasi Standar Nasional Indonesia (SISNI) 2016.

Badan Meteorologi, Klimatologi dan Geofisika. (2017). www.bmkg.go.id. Diakses pada tanggal 23 Oktober 2017.

Bakhri, Boy S. (2015). Kesiapan Indonesia Menghadapi Masyarakat Ekonomi ASEAN 2015 Dari Perspektif Daya Saing Nasional. ISEI

Bangun, W. (2014). Human Development Index: Enhancing Indonesian Competitiveness in ASEAN Economic Community ( $A E C$ ). International Journal of the Computer, the Internet and Management, 22(1), 4247.

Bertaria, Santosa, dan Rakhmawati. (2016). Jurnal Intra Universitas Kristen Petra. Vol. 4, No. 2, (2016). Hal. 195-202

Budiman, Aida S. (2012). Masyarakat Ekonomi ASEAN: Konsep Masyarakat Ekonomi ASEAN. Work Paper Direktorat Internasional, Jakarta.

European Commision for Standardization. (2013).

http://www.cen.eu/cen/Sectors/Technical CommitteesW

orkshops/CENTechnicalCommittees/Pag es/Standards. aspx ? param $=6188 \&$ title $=C$

EN/TC\%20207. diakses pada tanggal 20 Oktober 2013.

Feist, W. C. (1982). Weathering of wood in structural uses. In Structural use of wood in adverse environments (pp. 156-207). Van nostrand reinhold. New York.

Handayanto, E dan Hairiah, K. (2009). Biologi tanah landasan pengelolaan tanah sehat. Pustaka Adipura: Yogyakarta.

Indrawan. (2014), Peluang Ekspor Produk Kayu, Direktur Eksekutif Asosiasi Industri Permebelan dan Kerajinan Indonesia (Asmindo).

http://silk.dephut.go.id/index.php/article/v news/73 26/04/2014.

Iskandar. (2008). Metodologi Penelitian Pendidikan dan Sosial (Kuantitatif dan Kualitatif). Jakarta: GP Press.

International Standard Organization. (2013). http://www.iso.org/iso/home/store/catalog ue_tc/catalogue_tc_browse.htm?commid
$=52448$. diakses pada tanggal 20 Oktober 2013.

Kementerian Perindustrian (2016) Ekspor Impor Indonesia, Kementerian Perindustrian.

Kementerian Perdagangan Republik Indonesia. (2016) Statistik Perdagangan. Jakarta : Kementerian Perdagangan Republik Indonesia.

Kementerian Kehutanan. (2010). Buku Data dan Informasi Pemanfaatan Hutan Tahun 2010; Direktorat Jendral Planologi Kehutanan, Kementerian Kehutanan; November 2010.

Kementerian Kehutanan. (2003). Keputusan Menteri Kehutanan Nomor: 163/KptsII/2003 tanggal 26 Mei 2003 tentang Pengelompokan Jenis Kayu Sebagai Dasar Pengenaan Iuran Kehutanan. Jakarta.

Kementerian Kehutanan. (2012). Statistik Kehutanan Indonesia 2011. Jakarta

Martha, Mehdi dan Rusnaldy, (2012) Pengujian Sifat Mekanik Kayu Jati Untuk Aplikasi Furnitur. Undergraduate thesis, Mechanical Engineering Department, Faculty Engineering of Diponegoro University.

Moleong, Lexy J. (2008) Metodologi Penelitian Kualitatif, Bandung: PT Remaja Rosdakarya.

Nandika, D, Rismayadi, Y dan Diba, F.(2003). Biologi rayap dan pengendaliannya. Muhammadiyah Universitas Press: Surakarta.

Peraturan Pemerintah Republik Indonesia Nomor 102 Tahun 2000. Standardisasi Nasional. 10 November 2000. Lembaran Negara Republik Indonesia Tahun 2000 Nomor 1999 : Jakarta

Pemerintah Indonesia. (2014). Undang-Undang Nomor 20 Tahun 2014, tentang Standardisasi dan Penilaian Kesesuaian.Jakarta: Lembaran Negara Nomor 216 Tahun 2014.

Porter, M. E. (1990). The Competitive Advantage of Nations. Harvard Business Review, 68, 73-93.

Prasetyo, K.W dan Sulaeman Yusuf. (2005). Mencegah dan Membasmi Rayap Secara Ramah Lingkungan \& Kimiawi. Agromedia Pustaka. Bogor.

Rizki, K. A., Chairil Budiarto, dan Bambang Y. (2016), "Penerapan Material Kayu Pada Konstruksi Bangunan Kampung Lumbung di Kota Batu" Penerapan Material Kayu pada Konstruksi, ID 115350

Rusnaldy, Paryanto, Norman. (2009). Pengukuran Modulus Elastisitas 
Berbagai Jenis Kayu Untuk Furnitur. Jurnal Rotasi-Volume 11 Nomor 4. Oktober 2009. 11-14.

Samantha, R.F dan Barata Sena. (2017). Upaya Peningkatan Nilai Kayu Dengan Kreativitas Olah Kayu Menjadi Art Furnitur. Simposium Nasional RAPI XVI - 2017 FT UMS. Hal 240-247.

Susanta. (2007). Kiat Praktis Mencegah dan Membasmi Rayap, Jakarta. Penebar Swadaya.

Suwita, Imam (2016). Determination of Indonesia Furnitur Exports to the European and the Impact of Ecolabels. Thesis. Bogor
Postgraduate School, Agricultural University Bogor. Januari 2016.

Vukovic, D., Jovanovic, A., \& Djukic, M. (2012). Defining competitiveness through the theories of new economic geography and regional economy. Journal of the Geographical Institute Jovan Cvijic, SASA, 62(3), 49-64.

World Economic Forum (2014). The global competitiveness report 2014-2015. http://www.weforum.org/pdf/Global_Com petitiveness_Reports/Reports/factsheet gcr03.pdf. 
